\title{
Automatic ID Heat Load Generation in ANSYS Code
}

\section{Zhibi Wang}

\section{DISCLAIMER}

This report was prepared as an account of work sponsored by an agency of the United States Government. Neither the United States Government nor any agency thereof, nor any of their employees, makes any warranty, express or implied, or assumes any legal liability or responsibility for the accuracy, completeness, or usefulness of any information, apparatus, product, or process disclosed, or represents that its use would not infringe privately owned rights. Reference herein to any specific commercial product, process, or service by trade name, trademark, manufacturer, or otherwise does not necessarily constitute or imply its endorsement, recommendation, or favoring by the United States Government or any agency thereof. The views and opinions of authors expressed herein do not necessarily state or reflect those of the United States Government or any agency thereof.

\section{April 30, 1992}

\section{Experimental Facilities Division Advanced Photon Source Argonne National Laboratory}




\section{DISCLAIMER}

Portions of this document may be illegible in electronic image products. Images are produced from the best available original document. 


\title{
Automatic ID Heat Load Generation in ANSYS Code
}

\author{
Zhibi Wang
}

\section{Introduction}

Detailed power density profiles are critical in the execution of a thermal analysis using a finite element (FE) code such as ANSYS [1]. Unfortunately, as yet there is no easy way to directly input the precise power profiles into ANSYS. A straight-forward way to do this is to hand-calculate the power of each node or element and then type the data into the code (as in Ref. [2]). Every time a change is made to the FE model, the data must be recalculated and reentered. One way to solve this problem is to generate a set of discrete data, using another code such as PHOTON2, and curve-fit the data. Using curve-fitted formulae has several disadvantages. It is time consuming because of the need to run a second code for generation of the data, curve-fitting, and doing the data check, etc. Additionally, because there is no generality for different beamlines or different parameters, the above work must be repeated for each case. And, errors in the power profiles due to curve-fitting result in errors in the analysis. To solve the problem once and for all and with the capability to apply to any insertion device (ID), a program for ID power profile was written in ANSYS Parametric Design Language (APDL). This program is implemented as an ANSYS command with input parameters of peak magnetic field, deflection parameter, length of $\mathrm{ID}$, and distance from the source. Once the command is issued, all the heat load will be automatically generated by the code.

\section{Theoretical Power Profile}

A power profile for an ID can be written as [3]

$$
\frac{d P}{d \Omega}=\frac{d^{2} P}{d \theta d \psi}=P_{T} \frac{21 \gamma^{2}}{16 \pi K} G(K) f_{k}(\gamma \theta, \gamma \psi),
$$

which is a general formula for $\mathrm{dP} / \mathrm{d} \Omega$ for a sinusoidal electron trajectory. $\mathrm{P}_{\mathrm{T}}$ is the total power given by 


$$
P_{T}=\frac{N}{6} Z_{0} I \frac{2 \pi e c}{\lambda_{u}} \lambda^{2} K^{2}=0.633 E^{2}(G e V) B_{0}^{2}(T) L(m) I(A)(k W),
$$

where $\mathrm{N}$ is the number of periods, $\mathrm{Z}_{0}$ is the vacuum impedance, $\mathrm{I}$ is the electron current, $e$ is the electron charge, $\mathrm{c}$ is the velocity of light, $\mathrm{g}$ is the electron's relativistic energy/rest energy, $\mathrm{E}$ is the electron's energy, $\mathrm{L}$ is the length of the ID, and $\mathrm{G}(\mathrm{K})$ is a normalization factor given by

$$
G(K)=K \frac{\left(K^{6}+24 / 7 K^{4}+4 K^{2}+16 / 7\right)}{\left(1+K^{2}\right)^{7 / 2}} .
$$

Finally $f_{k}(\gamma \theta, \gamma \psi)$ is a factor that gives the angular dependence as follows:

$$
f_{k}(\gamma \theta, \gamma \psi)=\frac{16 K}{7 \pi G(K)} \int_{-\pi}^{\pi} d \alpha\left(\frac{1}{D^{3}}-\frac{4(\gamma \theta-K \cos \alpha)^{2}}{D^{5}}\right) \sin ^{2} \alpha,
$$

where

$$
D=1+(\gamma \psi)^{2}+(\gamma \theta-K \cos \alpha)^{2} .
$$

The function $\mathrm{f}$ is normalized so that

$$
f_{k}(0,0)=1
$$

Here, a second order numerical integration was used for eq. (4), and the algorithm was implemented within the ANSYS code. The code will automatically adjust the integration steps for the minimum error from the precise power profile.

The ANSYS command for power load generation has the form:

$$
H L O A D, B_{0}, K, L, D I S T
$$

where

$\mathrm{B}_{0}$ : peak magnetic field, in $\mathrm{T}$;

$\mathrm{K}$ : deflection parameter;

$\mathrm{L}$ : length of ID, in $\mathrm{m}$;

DIST: Distance from the source, in $\mathrm{m}$.

It can be used for any $\mathrm{ID}$ power profile. It has been checked with curvefitting formula for Undulator A, and the precise data for Wiggler A and Wiggler B from PHOTON2. The maximum difference from curve-fitting is about $10 \%$, and there is no difference between the results here and the precise power profiles. 


\section{The Use of the Command in ANSYS}

In order to execute the command, a user must copy a file from the ANSYS resident directory called "start.ans" to his home directory:

cp/home/attilla/ansys44a/bin/start.ans start.ans.

To run the command, the user need only select the elements on which the $\mathrm{x}$ ray beam impinges and set up a local coordinate system with the $\mathrm{X}$ axis in the horizontal direction, the $\mathrm{Y}$ axis in the vertical direction, and the $\mathrm{Z}$ axis in the beamline direction. The HLOAD command will automatically generate the thermal load for the selected elements.

\section{Example}

As shown in figure 1 , a rectangle plate of size 120 by $80 \mathrm{~mm}$ is subjected to the Wiggler A power from a distance of $29500 \mathrm{~mm}$ at an angle of 2.5 degrees. The plate has a thickness of $3.175 \mathrm{~mm}$ and is cooled by water at the opposite side with a convection coefficient $\mathrm{h}=3 \mathrm{~W} / \mathrm{cm}^{2}{ }^{\circ} \mathrm{C}$. The finite element code ANSYS was used for the thermal analysis. The mesh is shown in figure 1.

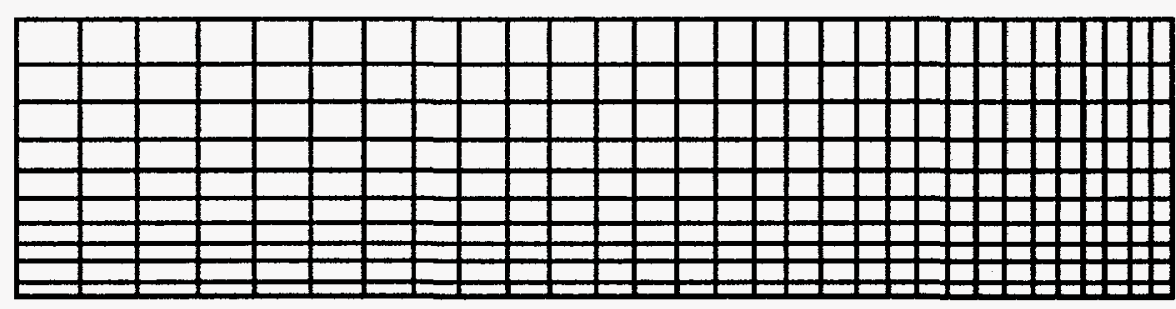

Figure 1. Finite element mesh

The thermal analysis of the ANSYS input is the following:

/prep7

kan,-1

ktemp,-1

et, 1,70

et, 2,57

$\mathrm{kxx}, 1,0.365$

ex, $1,130 \mathrm{e} 3$

nuxy, $1,0.326$ 


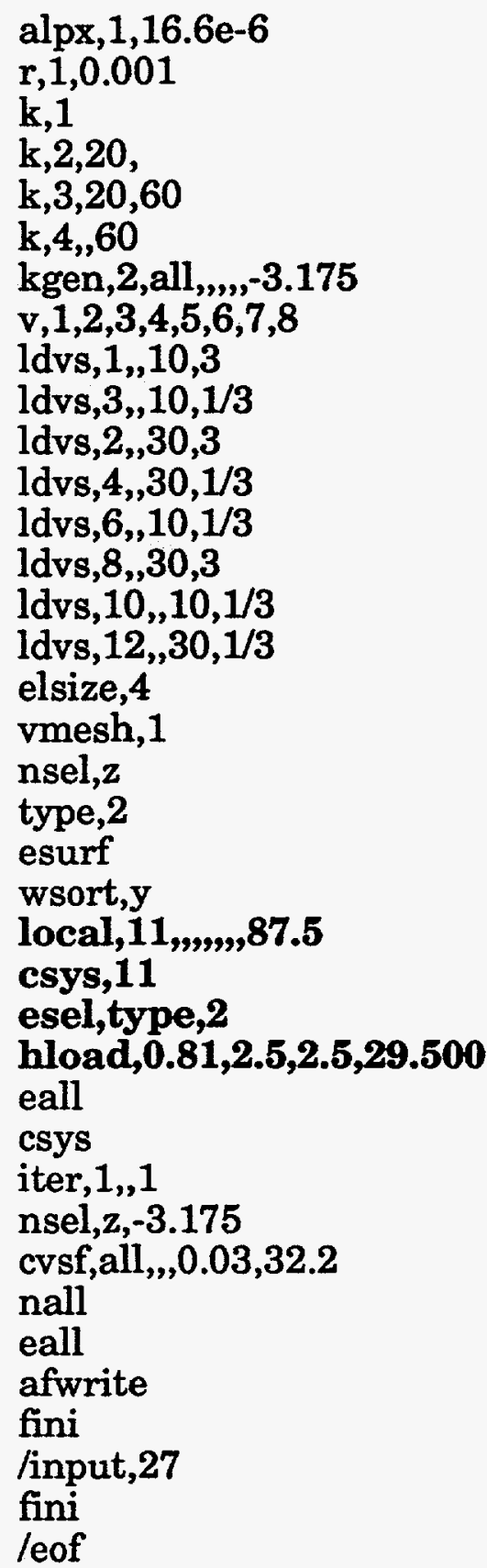

Isetup the local coordinate system !activate the local coordinate system tselect elements for power tuse of the command

The use of the command is highlighted in the above input file. The resulting power loading is shown in figure 2. 


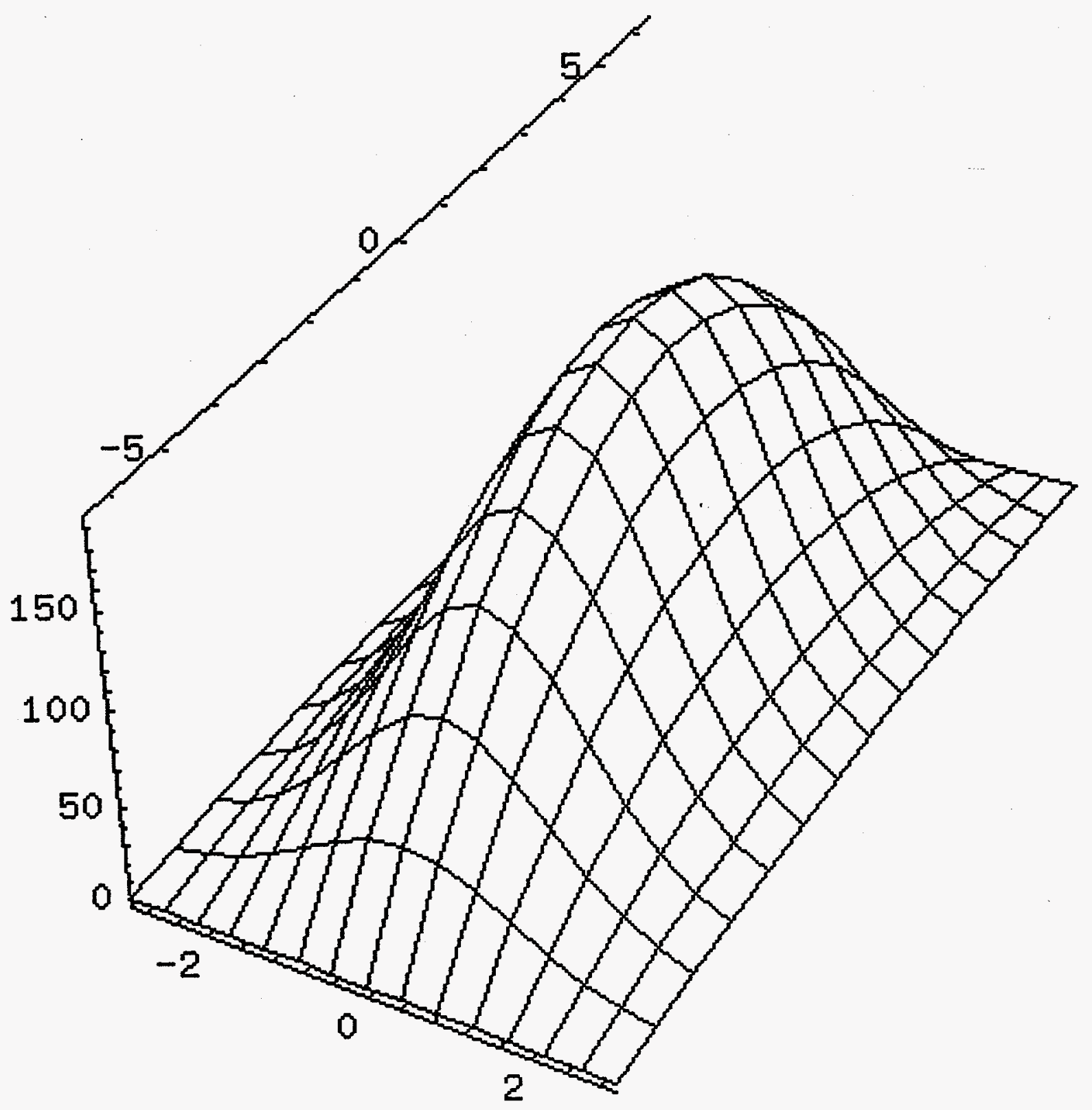

Figure 2 Power profile for the given example 
The ANSYS temperature contour is plotted in figure 3 , in which Tmin $=37^{\circ} \mathrm{C}$ and $\mathrm{Tmax}=192{ }^{\circ} \mathrm{C}$.

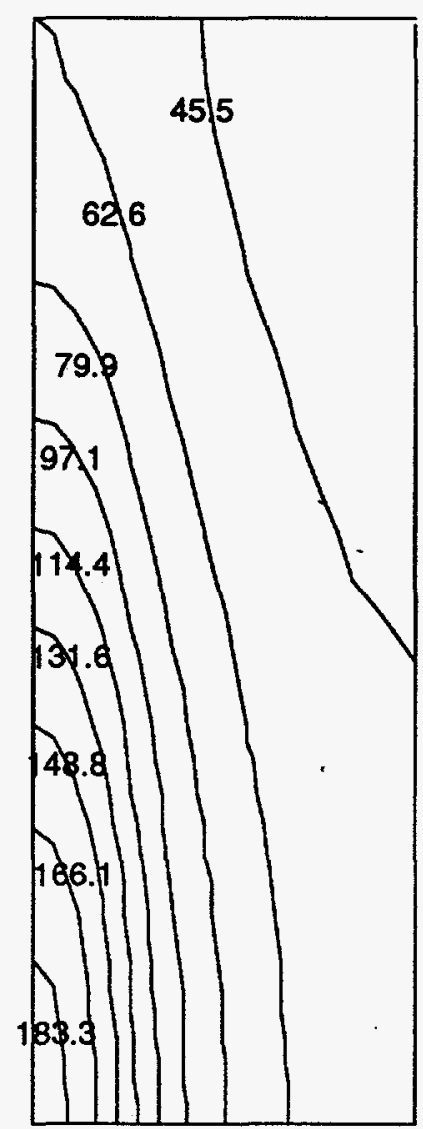

Figure 3 Temperature contour

\section{References}

1. Gabriel J. DeSalvo and Robert W. Gorman, ANSYS Engineering Analysis System User's Manual, May, 1989.

2. Thomas Swain, Engineering note, AL 2042, M7020, Lawrence Berkeley Laboratory, May 30, 1990.

3. K. J. Kim, Angular distribution of undulator power for an arbitrary deflection parameter K, Nucl. Inst. and Meth. A246, (1986) 67. 